Gut, 1985, 26, 1377-1379

\title{
Comparison between ranitidine and ranitidine plus Caved-S in the treatment of gastric ulceration
}

\author{
A G MORGAN, C PACSOO, AND W A F McADAM \\ From the Endoscopy Unit, Airedale General Hospital, Keighley, West Yorkshire
}

SUMmaRY In a double blind endoscopically controlled study, 100 patients with gastric ulcers were treated with either ranitidine or ranitidine plus Caved-S. On single therapy, $58 \%$ of ulcers were healed at four weeks, $92 \%$ at eight weeks and $96 \%$ at 12 weeks. Combination therapy did not alter the healing rate, nor improve on the control of dyspeptic symptoms. No difference in healing rate was found between good and poor drug compliance patients. This suggests that ranitidine may be equally effective at lower dosages. Thirty seven patients had developed their ulcer while taking non-steroidal anti-inflammatory drugs. These patients were mainly elderly women who had a higher risk of bleeding $(p=0.006)$ from a large ulcer $(p=0.009)$.

In a previous study ${ }^{1}$ we showed that cimetidine and Caved-S were equally effective in the treatment of gastric ulceration. As a gastric ulcer takes almost twice as long to heal as a duodenal ulcer, we suggested that combination therapy using an $\mathrm{H}_{2}$ receptor antagonist and a cytoprotective agent should be tried. This paper gives the results of such a study.

\section{Methods}

\section{PATIENTS}

One hundred patients with endoscopically proven benign gastric ulcers not already on an ulcer healing agent were entered into the study. They were randomly allocated to treatment with either ranitidine $150 \mathrm{mg}$ twice daily plus Caved-S two tablets three times a day, or ranitidine $150 \mathrm{mg}$ twice daily plus placebo Caved-S two tablets three times a day. Antacid therapy was limited to Rennies. Each patient was asked to record daily on a diary card antacid consumption, and the presence or absence of pain.

Endoscopy was repeated at four weekly intervals until ulcer healing was achieved. A treatment failure was defined as an ulcer unhealed after 12 weeks treatment, complications of drug therapy or uncontrollable symptoms.

Before each endoscopy, haematological and biochemical safety screening was carried out, any

Address for correspondence: Dr A G Morgan, Airedale General Hospital, Skipton Road, Steeton, Keighley, West Yorks BD20 6TD.

Received for publication 14 February 1985 side effects of treatment were noted and a return drug count undertaken.

All patients gave informed consent and the study was approved by the local hospital ethical committee.

\section{STATISTICAL METHODS}

Healing rates were compared between treatments using a log rank test from a life table analysis. The proportions of patients with healed ulcers at four weeks were compared between levels for the baseline factors (Table 1) using tests based on the $\chi^{2}$ test.

Healing rates within levels of each of 21 possible pairs of baseline factors were calculated using a logistic model fitted to the counts in each two way table using a GLIM program to look for the presence of interactions between these factors.

\section{Results}

One hundred patients were entered into the study between August 1981 and October 1983. The two treatment groups were evenly matched with regard to the principal characteristics (Table 1). The healing rates for the two treatment groups were similar with a mean value of $58 \%$ healed at four weeks, $87 \%$ at eight weeks and $95 \%$ at 12 weeks (Table 2).

No clinically significant side effects were seen. Diary card analysis showed similar results for both treatment groups with good control of pain by the end of the first week of treatment (Figure).

Thirty seven per cent of the patients were taking 
Table 1 Comparability of two treatment groups

\begin{tabular}{lcc}
\hline & \multicolumn{2}{c}{ Treatment group } \\
\cline { 2 - 2 } & Ranitidine & Ranitidine + Caved-S \\
\hline Age (yr) & \\
$\quad$ Mean (SD) & $61 \cdot 5 \pm 14 \cdot 5$ & $64 \cdot 7 \pm 10 \cdot 4$ \\
Sex & & \\
Male & 16 & 14 \\
Female & 34 & 36 \\
Length of history (weeks) & & \\
range & $2-1664$ & $0-1820$ \\
median & 156 & 104 \\
Smokers & 24 & 26 \\
Drinkers & 29 & 22 \\
Ulcer size & & \\
small & 7 & 9 \\
medium & 24 & 25 \\
large & 19 & 16 \\
$\quad$ multiple & 5 & 9 \\
Ulcer site & & \\
antrum & & \\
incisura & & 7 \\
body & & 5 \\
$\quad$ high lesser curve/fundus & 16 & 21 \\
Multiple ulcers & 5 & 9 \\
Past history of ulcer & & \\
duodenal ulcer & 3 & 6 \\
gastric ulcer & 12 & 9 \\
NSAI drug-related ulcer & 16 & 21 \\
\hline
\end{tabular}

non-steroidal anti-inflammatory (NSAI) drugs before the diagnosis of the ulcer. These patients were slightly older, with a higher female/male ratio, and a higher incidence of acute bleeding from a large ulcer (Table 3).

Drug compliance for the first month of therapy
Table 2 Results of treatment and compliance on ulcer healing

\begin{tabular}{llll}
\hline & \multicolumn{3}{l}{ Healed ulcers at } \\
\cline { 2 - 4 } Treatment group & 4 weeks & 8 weeks & 12 weeks \\
\hline Ranitidine (50) & $29(58 \%)$ & $46(92 \%)$ & $48(96 \%)$ \\
Ranitidine + Caved-S (50) & $29(58 \%)$ & $41(82 \%)$ & $47(94 \%)$ \\
Poor compliance (16) & $62 \%$ & $94 \%$ & $100 \%$ \\
Good compliance (69) & $51 \%$ & $83 \%$ & $94 \%$ \\
\hline
\end{tabular}

was available for 85 patients. Sixteen returned more than five days supply, seven from the single therapy group (mean 8.6 days) and nine from the combined group (mean 8.4 days). Healing rates were not affected by compliance (Table 2 ). The ratio of ulcer size was similar for the two groups.

Of the factors listed in Table 1, only initial ulcer size was found to affect healing rates, with larger ulcers taking longer than small ulcers $(p<0 \cdot 001)$. The effect on healing rates for each of the 21 possible pairs of attributes were calculated. The only significant finding was that in the group of patients who had taken NSAI drugs, the proportion of women with healed ulcers at four weeks (nine out of 29) was less than for the men (eight out of eight) $(p<0.001)$. This difference may be explained by the fact that 18 out of the 29 women had a large ulcer (62\%) compared with only one out of eight men $(13 \%)$.

\section{Discussion}

Although most patients with gastric ulceration are
Figure Effect of treatment on dyspeptic symptoms. (Pain score - mild $=1$, moderate $=2$, severe $=3$ ).
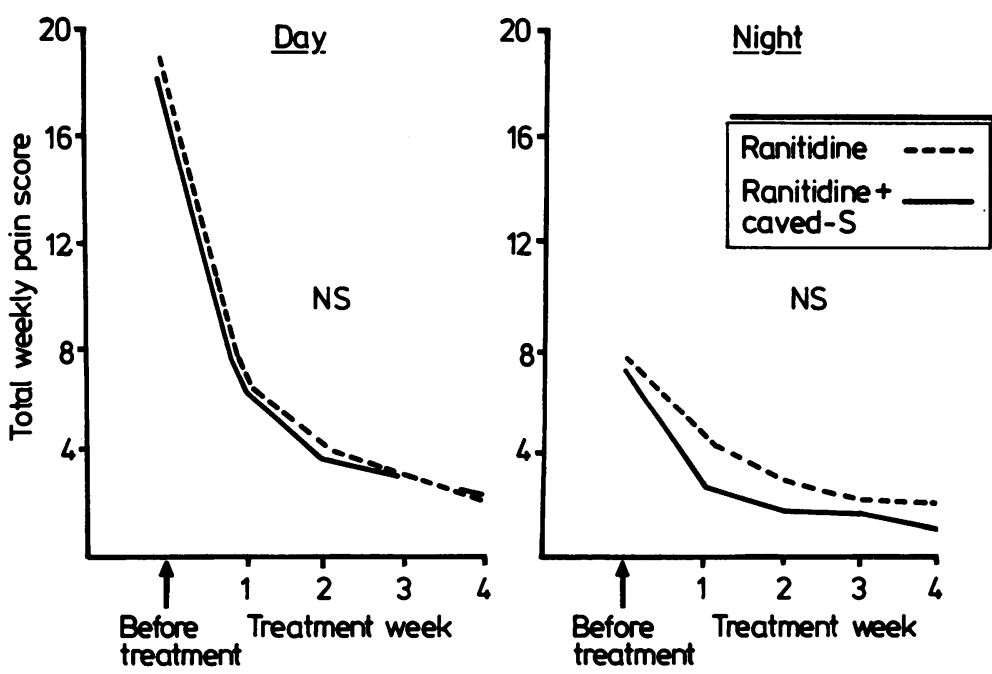
Table 3 Comparison between drug-related (NSAI drugs) and non-drug-related ulcers

\begin{tabular}{lll}
\hline & NSAI drug (37) & No drug (63) \\
\hline Average age & 67 & 60 \\
Sex M & 8 & 22 \\
$\quad$ F & $29(78 \%)$ & $41(65 \%)$ \\
Acute bleeding & $15(41 \%)$ & $10(16 \%) \mathrm{p}=0.006$ \\
Large ulcers & $19(51 \%)$ & $16(25 \%) \mathrm{p}=0.009$ \\
\hline
\end{tabular}

treated with either ranitidine or cimetidine, the healing rates for pirenzipine, DeNol, sucrulfate, carbenoxolone and Caved-S are similar. ${ }^{1-10}$ As gastric ulcers take longer to heal than duodenal ulcers, drug combinations have been tried. The combination of cimetidine with antacids ${ }^{11}$ or anticholinergics ${ }^{12}$ has been used without success. Minoli et al combined cimetidine with carbenoxolone and showed a non-significant trend at three weeks in favour of the dual therapy. ${ }^{13}$

In 1982 we showed that cimetidine and Caved-S were equally effective in healing gastric ulcers ${ }^{1}$ and suggested combination therapy. In this study, ranitidine has been compared with ranitidine plus Caved$\mathrm{S}$, and no beneficial effect was shown. The healing rate for the ranitidine only group was similar to other studies and no significant side effects were encountered. Both treatment regimes were equally effective in controlling symptoms.

This study has shown the importance of nonsteroidal anti-inflammatory (NSAI) drugs in the pathogenesis of gastric ulceration. Thirty seven per cent of our patients were on such drugs, of whom slightly over $75 \%$ were women. We also confirm previous reports in which NSAI drug treatment has been shown to result in large ulcers which bleed. ${ }^{114}$ Ulcer healing rate is, however, the same for drug-related and non-drug-related ulcers. The only attributes found to affect ulcer healing was ulcer size, large ulcers, as would be expected, take longer to heal than small or medium sized ulcers $(\mathrm{p}<0 \cdot 001)$.

The return drug count was available for 85 patients. The healing rate for the group of poor compliance patients was similar to the good tablet takers, and this suggests that the effect of ranitidine may be maximal at a dose smaller than $150 \mathrm{mg}$ bd.

As the combination of ranitidine and Caved-S has failed to accelerate gastric ulcer healing, it will be interesting to see if treatment with the new synthetic prostaglandins will be any more effective. In the meantime, ranitidine, cimetidine or Caved-S would seem to remain the drugs of choice in gastric ulcer therapy.
The authors acknowledge with grateful thanks the help and support of Glaxo Group Research Limited and Tillotson Laboratories in the running of this study, and to Mr Michael of the Glaxo Group Research Limited for the statistical analyses.

\section{References}

1 Morgan AG, McAdam WAF, Pacsoo C, Darnborough A. Comparison between cimetidine and Caved-S in the treatment of gastric ulceration, and subsequent maintenance therapy. Gut 1982; 23: 545-51.

2 The Belgian Peptic Ulcer Study Group. Single blind comparative study of ranitidine and cimetidine in patients with gastric ulcer. Gut 1984; 25: 999-1002.

3 Baron JH, Perrin VL, Barnardo DE et al. Gastric ulcer healing with ranitidine and cimetidine. Scand J Gastroenterol 1983; 18: 973-6.

4 Wright JP, Marks IN, Mee AS et al. Ranitidine in the treatment of gastric ulceration. $S$ Afr Med J 1982; 61: 155-8.

5 Morelli A, Pelli A, Narducci F, Spadacini A. Pirenzipine in the treatment of gastric ulcer. A double blind short-term trial. Scand J Gastroenterol 1979; 14: suppl 51-5.

6 Lahtinen J, Aukee S, Miettinen P, Poikolainen E, Pääkkönen M, Sandström R. Sulcralfate and cimetidine for gastric ulcer. Scand J Gastroenterol 1983; 18: suppl 83: Proceedings of the 2nd International Sucralfate Symposium. The 7th World Congress of Gastroenterology, Stockholm 1982; 49-51.

7 Sutton DR. Gastric ulcer healing with tripotassium dicitrato bismuthate and subsequent relapse. Gut 1982 ; 23: 621-4.

8 Tytgat GNJ, Van Bentem N, Van Olffen G, Dekker W, Rutgeerts L, De Boer J. Controlled trial comparing colloidal bismuth subcitrate tablets, cimetidine and placebo in the treatment of gastric ulceration. Scand $J$ Gastroenterol 1982; 17: suppl 80: Proceedings of the De Nol symposium. The 7th World Congress of Gastroenterology, Stockholm 1982: 31-8.

9 La Brooy SJ, Taylor RH, Hunt RH et al. Controlled comparison of cimetidine and carbenoxolone sodium in gastric ulcer. Br Med J 1979; 1: 1308-9.

10 Petrillo M, Porro GB, Valentini M, Dobrilla G. Cimetidine and carbenoxolone sodium in the treatment of gastric ulcer: an open pilot study. Curr Ther Res 1979; 26: 990-4.

11 Rune SJ, Jensen KG, Wulff HR et al. Additional antacid does not increase the effect of cimetidine in gastric ulcer disease. Scand J Gastroenterol 1984; 19: 56-8.

12 Paerregaard A, Hendel L, Schultz-Larsen K, Tobiasen K, Mosbech J. Treatment of gastroduodenal ulcers with cimetidine in combination with low-dose propantheline. Acta Med Scand 1983; 213: 195-8.

13 Minoli G, Terruzzi V, Ferrara A et al. The association of cimetidine and carbenoxolone in the treatment of gastric ulcer. [Abstract 401] Scand J Gastroenterol 1982; 17: suppl 78: 101.

14 Cooke P, Thompson MR. Old ladies, drugs and gastric ulceration. [Abstract]. Gut 1981; 22: A430. 